\title{
Influence of Carding and Pressing on Hygrothermal Properties and Fire Reaction of Hemp Fiber Nonwoven Mats
}

\author{
Antonio Donatelli ${ }^{1 *}$, Patrizia Aversa ${ }^{1}$, Roberto Terzi ${ }^{1}$, Tommaso Marcianò ${ }^{1}$, Luca Laghi ${ }^{2}$, \\ Giulia De Aloysio ${ }^{2}$, Wanda Arena ${ }^{3}$, Vincenza A.M. Luprano ${ }^{1}$ \\ 1. ENEA - Italian National Agency for New Technologies, Energy and Sustainable Economic \\ Development, SS Appia 7, $\mathrm{km}$ 706.00, 72100 Brindisi, Italy \\ 2. CertiMaC ScarL, Via Granarolo 62, Faenza (RA), Italy \\ 3. CETMA, SS Appia 7, $\mathrm{km}$ 706.00, 72100 Brindisi, Italy \\ *E-mail: antonio.donatelli@enea.it
}

\begin{abstract}
This article depicts the effect of carding and pressing on hygrothermal properties of hemp fibers nonwoven mats, trying to understand if their implementation can improve their behavior when employed as insulation materials in buildings. Hemp fibers belonging to Cannabis Sativa species and coming from local area (Apulia - Italy) were examined, then samples of carded and pressed hemp fibers nonwoven mats were prepared. According to European standards, the thermal conductivity, the vapor permeability and the fire reaction of hemp fibers samples were measured. Results were compared to each other and with those of a commercial nonwoven mat made with hemp (90 wt. \%) and synthetic fibers (10 wt. \%), used as reference. We observed that carded and pressed hemp fibers were characterized by a lower thermal conductivity when compared to unprocessed hemp fibers, likely because the removing of wood elements. On the other hand, not processed hemp fibers show higher breathability when compared to carded and pressed ones, as well as with respect to the commercial nonwoven mat. Moreover, it was proved that the absence of synthetic commingled fibers in hemp fibers allows a better behavior in fire reaction. At last, the improvement in terms of insulation properties of a hollow brick when filled with hemp fibers was verified, by comparing the thermal conductivities of an empty and a filled hollow brick; as expected, the filled hollow brick shows a lower thermal conductivity, underlining the effectiveness of hemp fibers as insulation material.
\end{abstract}

Keywords: Hemp; building; thermal conductivity; vapor permeability; fire reaction.

\section{Introduction}

Together with Industrial and Transportation sectors, the Building sector is considered one of the major responsible of worldwide energy consumption. In particular, Buildings are responsible for about 30-45\% of the global energy consumption [1] and the improving in quality life and climate change predicted in the next years will entail the increasing of this rate [1, 2]. Based on this evidence, particular attention must be paid to the reduction of energy consumption in buildings worldwide, moving toward the concept of near zero energy building (nZEB). The Energy Performance of Building Directive (EPBD) introduces the following definition of a ZEB, in the article 2 of Directive 2010/31/EU: “... a building that has a very high energy performance, as determined in accordance with Annex I. The nearly zero or very low amount of energy required should be covered to a very significant extent by energy from renewable sources, including energy from renewable sources produced on-site or nearby" [3].

The first step to achieve these targets is to ensure that the opaque walls of a building had high thermal resistance values, in order to minimize the heat waste towards the outside in the cold months. There are many petroleumderived materials that can ensure high thermal insulation (XPS, EPS, PUR, etc.), but their production requires very high processing temperatures and, in many cases, they cannot be recycled [4, 5].

Since several years also natural materials that can assure similar thermal insulation properties but greater sustainability with respect to the petroleum-derived ones, have begun to spread. Among them, the employment of hemp fibers as insulation has been already investigated in recent years [6, 7] and commonly in the form of bioaggregate-based composites [6, 8, 9]. An alternative application is the use of hemp fibers as nonwoven mats, or in the form of bulk material for example to fill the holes of common hollow brick; in last years, we investigated this approach noticing an improvement in the dynamic thermal behavior. Indeed, the presence of the hemp fibers in the hollow bricks determines a decreasing in the decrement factor and an increasing in the time lag with respect to empty bricks [10].

When insulating based on cellulosic fibers are used, particular attention must be devoted to degradation due to microbial contamination. Delannoy et al. [11] investigated the long thermal behavior of hemp shiv, comparing a 
natural aging with accelerated aging conditions based on humidification and drying cycle. They found that fungal attacks alter the microstructure of the hemp shiv, and therefore its functional properties. Conversely, in a previous study we investigated whether a degradation of the hemp fibers could occur during their lifetimes in Mediterranean Area [12]. Some hemp fibers were artificially contaminated with microorganisms and after the execution of accelerated weathering cycle we found that none of the isolated microorganisms caused any types of changes, as appearance, color, weight or rotting.

In addition, one of the main characteristic of insulating based on cellulosic fibers is a high sensitivity to moisture, due to the presence of $\mathrm{OH}$ groups which are the main responsible for the absorption of water particles $[13,14]$. Therefore, particular attention must be devoted on the behavior of hemp fibers when high levels of moisture are present. Several papers in literature report the negative effect of water absorption of the hemp fiber when used in composite materials. In particular, the exposure to moisture results in significant drops in tensile and flexural properties due to the degradation of the fiber-matrix interface $[15,16]$. On the other hand, Latif et al. [17] explored the effects of high, normal and low internal moisture loads on wall panels with wood-hemp composite insulation, in particular with and without a vapor barrier. They found that the temperature and the exposure conditions in the insulation and oriented strand board (OSB) interfaces of the panel without a vapor barrier were found to be more favorable to the germination of mould spores. Nonetheless, when the insulations were dismantled, no mould was visually detected.

Moreover, as all cellulosic fibers, also hemp fibers are flammable and therefore the use of fire retardant are commonly investigated to reduce fire risk [18].

In the present work, further investigations about the behavior of hemp fibers when used as insulating have been carried out. In particular, the aim of our activities was to understand whether some mechanical operations like pressing or carding of the hemp fibers could influence their thermal conductivity or their vapor permeability, and comparing them with those of a commercial insulation mat made with hemp and synthetic fibers. Furthermore, we investigated whether pressing or carding could modify the reaction to the fire performance of hemp fibers. Lastly, the effectiveness of the presence of hemp fibers in the holes of hollow bricks has been investigated, comparing the thermal conductivities of empty and filled bricks.

\section{Infrastructure and methodology}

\subsection{Pressing}

Pressing was carried out with a hot plate press branded Collin P 300 P/M (Figure 1). Working parameters of the press were: maximum force $30 \mathrm{kN}$, maximum temperature $300{ }^{\circ} \mathrm{C}$, minimum pressure $0.2 \mathrm{bar}$.

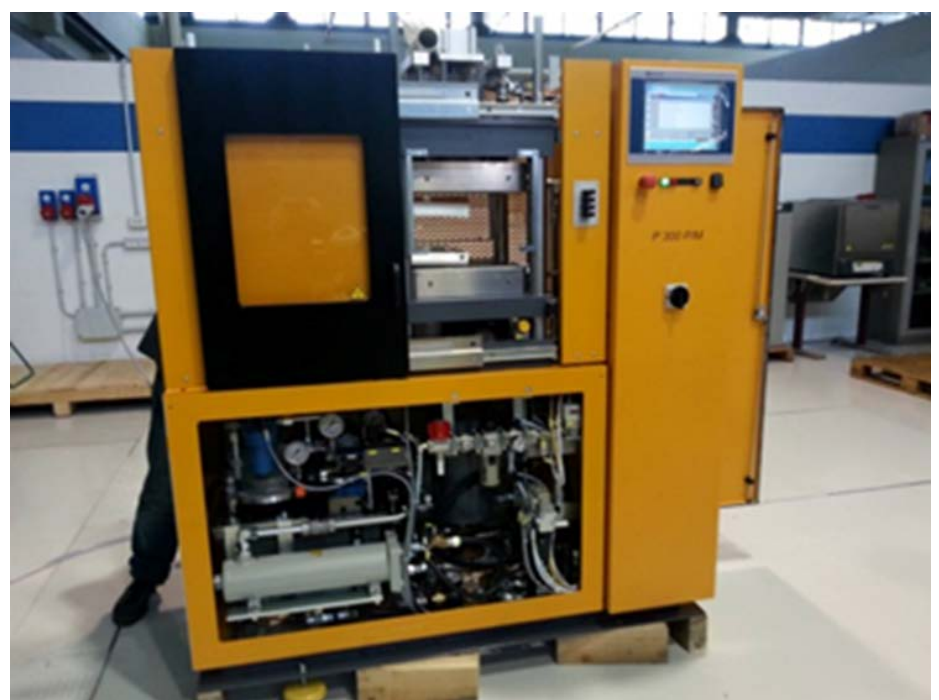

Figure 1. Hot plate press: Collin P 300 P/M

The press cycle was set to obtain a mat with a thickness of $26 \mathrm{~mm}$ starting from four overlapped rectangular mats of hemp fibers (Cannabis sativa) came from local crops in Puglia, Apani locality near Brindisi, Italy and having a thickness of $60 \mathrm{~mm}$, length of $1200 \mathrm{~mm}$ and width of $600 \mathrm{~mm}$. More in detail, the work pressing cycle was as follow:

1) heating of press plates from $60{ }^{\circ} \mathrm{C}$ to $140{ }^{\circ} \mathrm{C}$ in 5 minutes and under atmospheric pressure;

2) when the temperature of $140{ }^{\circ} \mathrm{C}$ was reached, the pressure was increased up to 2 bar in 5 minutes. 
At the end of the press cycle, square mats of hemp fibers with side length of $300 \mathrm{~mm}$ and a thickness of $26 \mathrm{~mm}$ were obtained.

\subsection{Carding}

Carding was carried out with a carding machine branded MESDAN, based on a comb drum technology (Figure 2). Starting from local hemp fibers, some oriented hemp fibers mats were realized, having side length of $540 \mathrm{~mm}$, width of $200 \mathrm{~mm}$ and thickness of $60 \mathrm{~mm}$ and. The local hemp showed a high concentration of wood matrix, therefore an exfoliation of starting materials was necessary before carding, to partially remove the wood fraction.

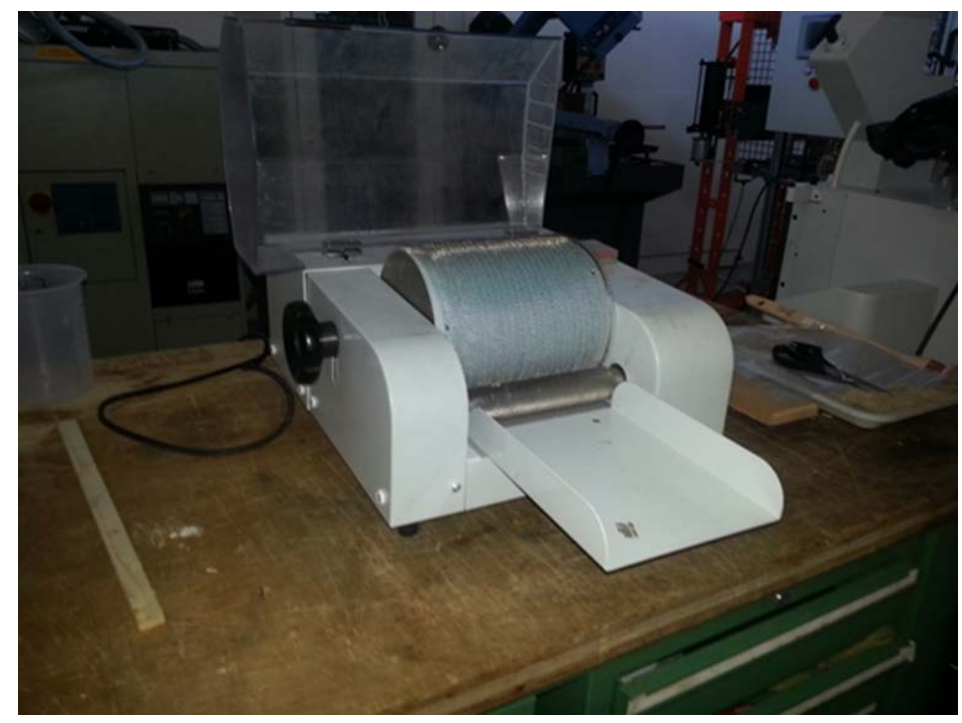

Figure 2. Carding machine branded MESDAN

\subsection{Thermal conductivity}

A DTC-300 Heat Flow Meter (Figures 3 and 4) was employed for the determination of thermal conductivity, by means of the guarded heat flow meter method [19, 20] and in accordance with ASTM E1530-2011, Standard Test Method for Evaluating the Resistance to Thermal Transmission of Materials by the Guarded Heat Flow Meter Technique. This test method covers a steady-state technique for the determination of the resistance to thermal transmission (thermal resistance) of materials whose specimen thicknesses is less than $25 \mathrm{~mm}$.
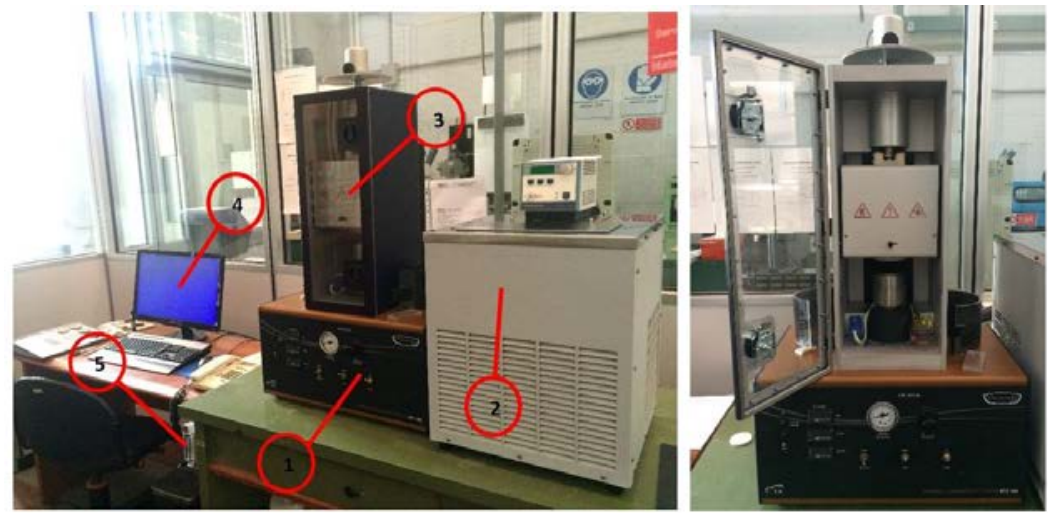

Figure 3. Thermo-physic measurement laboratory at CertiMaC, in Faenza. (1) Command and Control Panel in order to supervise the temperatures along the stack and the cylinder pressure. (2) Chiller with temperature automatic controller. (3) Stack section with HFM and Guard Heater. (4) Personal Computer with software and acquisition system. (5) Control and Command Panel for air and nitrogen system.

A specimen and a Heat Flow Transducer (HFT) are sandwiched between two flat plates controlled at different temperatures to produce a heat flow through the test stack. The lower contact surface (with the sample) is part of a calibrated HFT. A reproducible load is applied to the test stack by a pneumatic cylinder, to ensure that there is a reproducible contact resistance between the specimen and plate surfaces. A guard surrounding the test stack is maintained at a uniform mean temperature of the two plates, in order to minimize lateral heat flow to and from the stack. Moreover, the guard is replaced by an insulating ring when the test mean temperature is under $20^{\circ} \mathrm{C}$, in 
cryogenic conditions. As heat flows from the upper surface through the sample to the lower surface, an axial temperature gradient is established in the stack and at steady state, the difference in temperature between the surfaces contacting the specimen is measured with temperature sensors embedded in the surfaces, together with the electrical output of the HFT (Figure 4). This output (voltage) is proportional to the heat flow through the specimen, the HFT and the interfaces between the specimen and the apparatus. The proportionality is obtained through prior calibration of the system with six specimens of known and certificated thermal resistance measured under the same conditions, in the way that the contact resistance at the surfaces is made reproducible. The thermal conductivity determination of an unknown specimen shall be conducted at a temperature within a certain range and under applied load conditions for which valid calibration data exist.

The measurement of the thermal conductivity was carried out on different kind of hemp samples in dry conditions and at the average temperature of $10^{\circ} \mathrm{C}$. Samples, reported in Figure 5, were:

1) local hemp in the form of bulk material, not pressed and not carded (referred as "as it is" hemp) (H);

2) local hemp not pressed and carded in layer $(\mathrm{CH})$;

3) local hemp pressed and carded (CPH);

4) commercial hemp with 10 wt.\% of synthetic fibers (HSF)

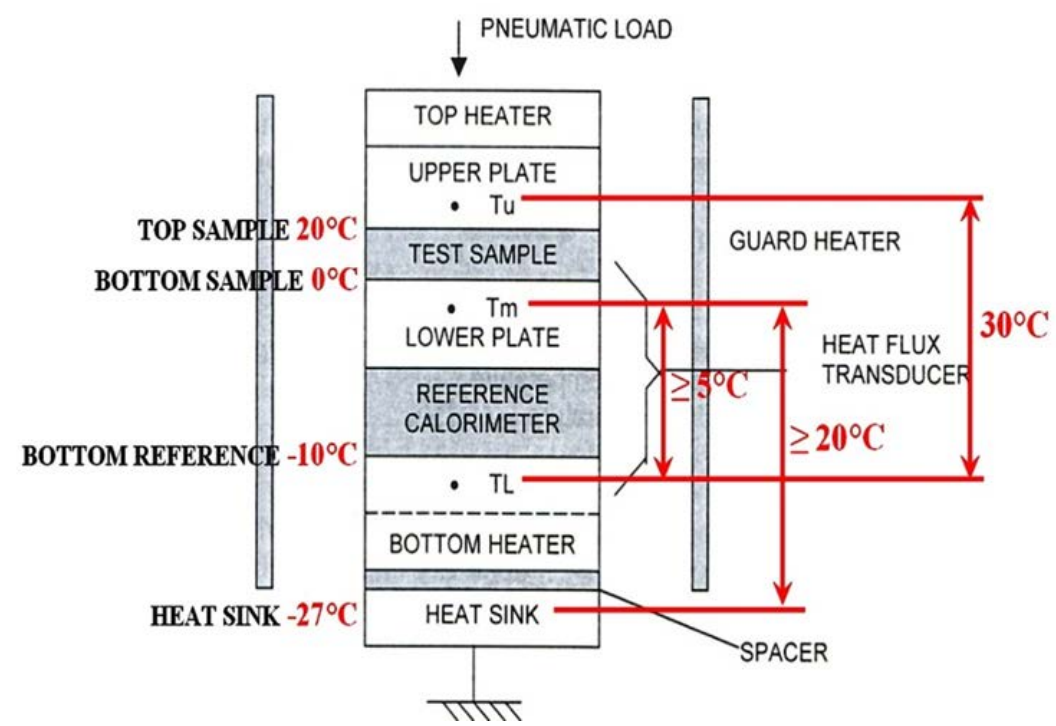

Figure 4. Test section schematic - temperature setting for $10^{\circ} \mathrm{C}$ measurement.

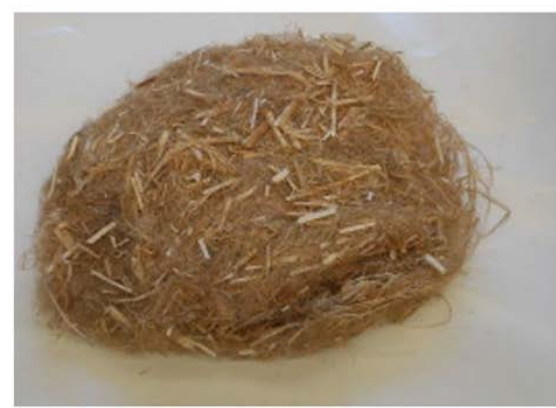

(a)

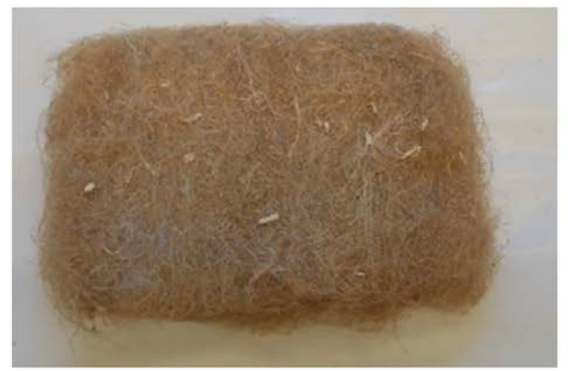

(c)

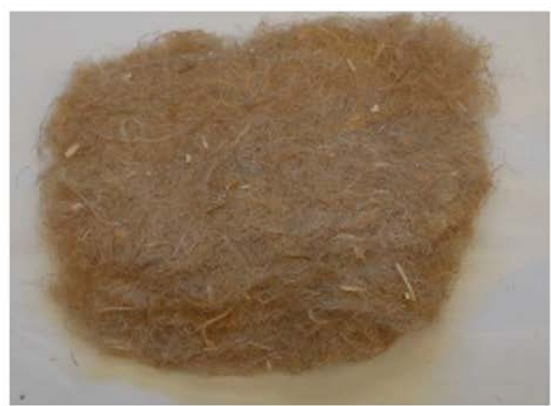

(b)

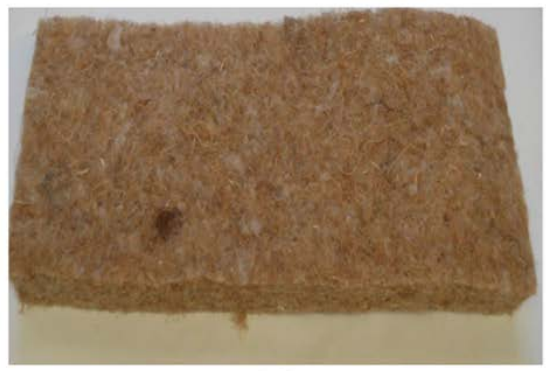

(d)

Figure 5. Samples of nonwoven hemp: H (a), CH (b), CPH (c), HSF (d). 
For each material, circular-shape samples with a diameter measuring approximately to $50.8 \pm 0.25$ mm were produced, according to standard EN 12667:2002 [21]. Then they were conditioned in a ventilated oven at $50{ }^{\circ} \mathrm{C}$ until the dry state was reached and then, the density measurements on the sample were carried out.

As reported in the standard, for measurements performed on non-homogeneous samples it is not possible to provide guidelines for assessing the accuracy of the measurement when the homogeneity requirement is not met, as in this case.

In addition, a $\lambda$-Meter EP 500 instrument (Me $\beta$ technik GmbH Dresden) was used for the determination of thermal conductivity of hollow bricks and according with standard EN 12664:2002 [22]. Before, hemp fibers were dried in an oven, until a constant mass is reached (within $0.1 \mathrm{~kg} \cdot \mathrm{m}^{-3}$ in $24 \mathrm{~h}$ ). At the end of the drying step, hemp fibers were inserted in some hollow bricks with size $25 \mathrm{~cm}$ (Figure 6) to undergo the thermal conductance test. Measurements were performed on both empty and filled hollow bricks.

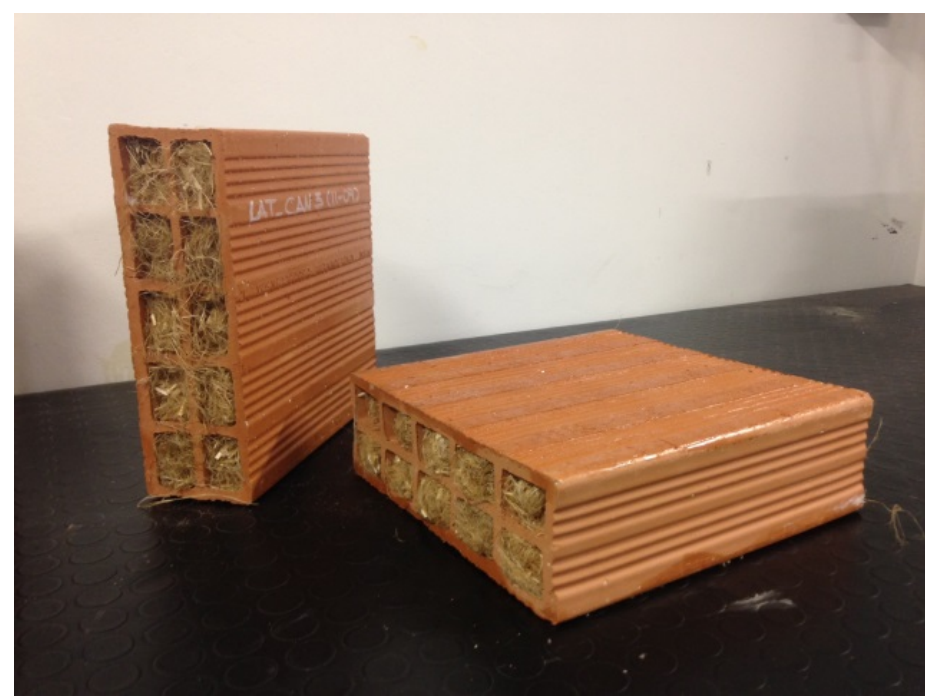

Figure 6. hollow bricks filled with hemp fibers.

\subsection{Vapor permeability}

Tests for the determination of water-vapor transmission properties of hemp fiber were performed in compliance with EN ISO 12572 standard by means of a testing apparatus specifically produced based on the indications provided by the same standard. The scheme of the apparatus is reported in Figure 7a. A picture of the equipment actually used is reported in Figure 7b.

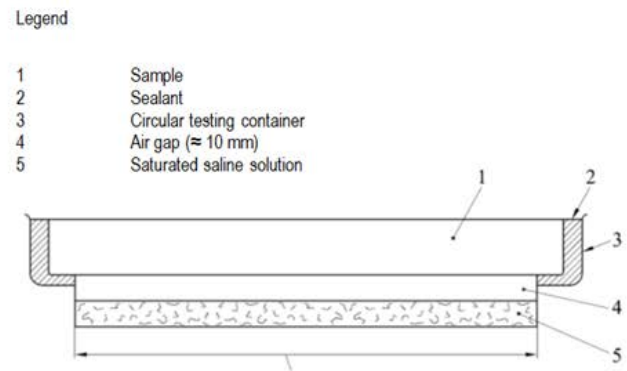

(a)

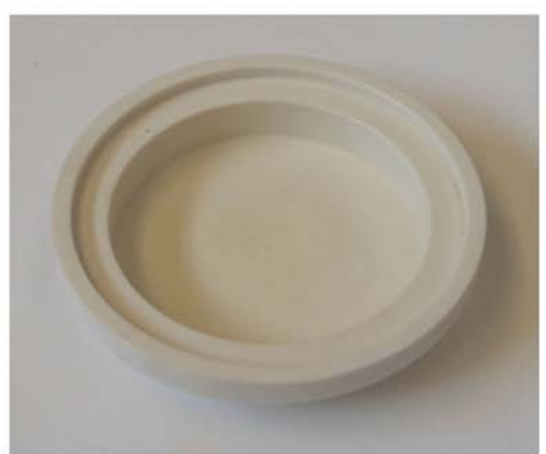

(b)

Figure 7. Testing apparatus: scheme (a) and apparatus in PVC used at the Laboratory (b).

The equipment complies with mandatory requirements and has the following characteristics:

1) Exchange surface: $\approx 0.0058 \mathrm{~m}^{2}$, from which follows a diameter of $80 \mathrm{~mm}$;

2) Lower compartment to hold saturated KNO3 saline solution, needed to guarantee the conditions of relative humidity;

3) Air gap of $15 \pm 5 \mathrm{~mm}$ between the inferior surface of the sample and the surface of the solution;

4) Upper compartment with a dimension suitable to host circular-shaped specimens representative of the products to be tested. 
EN ISO 12572 sets the methods to determine water-vapor transmission properties for building products in steady-state flow, for pre-determined and constant conditions of relative humidity. These conditions are guaranteed using a saturated saline solution of ${ }_{\mathrm{KNO}}$ (Potassium Nitrate), which at the temperature of $20^{\circ} \mathrm{C}$ guarantees a relative humidity level of $93.2 \%$. Containers with the samples conveniently sealed along the circumferential perimeter are placed in a controlled environment $\left(20^{\circ} \pm 2^{\circ} \mathrm{C}\right.$ e $50 \pm 5 \%$ R.U.), where the vapor pressure is maintained at a different level than the one inside the containers in order to guarantee the presence of a pressure gradient able to create diffusion phenomena as described by Fick's laws.

The water-vapor flow rate, referred as G, is evaluated in steady-state and one-dimensional conditions, starting from the mass variation of the sample-container ensemble. More specifically, in order to increase the rate of flow of water-vapor and thus facilitating the diffusion phenomenon, humidity conditions outside the sample were fixed using a saturated $\mathrm{LiCl}$ solution, guaranteeing a constant relative humidity at $20^{\circ} \mathrm{C}$ nominally equal to $11 \%$ (about 18.9 at thermal equilibrium).

This process, repeated over time at appropriate intervals, allows us to determine when the linear mass variation is achieved. This condition is graphically observable by relating mass and time when subsequent points lie on a straight line. From such correlation, it is possible to determine G, the slope of the line excluding the earlier transitory stage of the test.

The rate of flow of water vapor is a prerequisite for the determination of the water-vapor permeance (transmission rate) W (1) and of the water-vapor resistance factor $\mu$ (2):

$$
\mathrm{W}=\mathrm{G} /(\mathrm{A} \cdot \Delta \mathrm{pv})
$$

where:

$\mathrm{W}=$ Water-vapor permeance $\left(\mathrm{kg} \cdot \mathrm{m}^{-2} \cdot \mathrm{Pa}^{-1} \cdot \mathrm{s}^{-1}\right)$;

$\mathrm{G}=$ Water-vapor flow rate $\left(\mathrm{kg} \cdot \mathrm{s}^{-1}\right)$;

$\mathrm{A}=$ Exposed area of the test specimen $\approx 0.015 \mathrm{~m}^{2}$;

$\Delta \mathrm{pv}=$ difference between the partial water-vapor pressure in the test cup and that in the test enclosure (Pa); from which:

$\mu=\delta a /(W \cdot d)$

where:

$\mu=$ water-vapor resistance factor (-);

$\delta \mathrm{a}=$ Water-vapor permeability of air, evaluated through Schirmer formula $\left(\mathrm{kg} \cdot \mathrm{m}^{-1} \cdot \mathrm{s}^{-1} \cdot \mathrm{Pa}^{-1}\right)$;

$\mathrm{d}=$ average sample thickness $(\mathrm{m})$.

Samples to be tested were self-supporting and hence the mechanical measurement of the thickness through a sensing probe with a resolution of $\pm 5 \mu \mathrm{m}$ was not necessary. Figure 8 shows a test apparatus with one sample of hemp fiber disc.

The test were carried out on five samples, cut out from the starting different type of hemp sent to the Laboratory. The preparation phase included the production of circular-shaped samples with a diameter measuring approximately $95 \mathrm{~mm}$. Prior to testing, samples had been conditioned in laboratory environment for seven days.

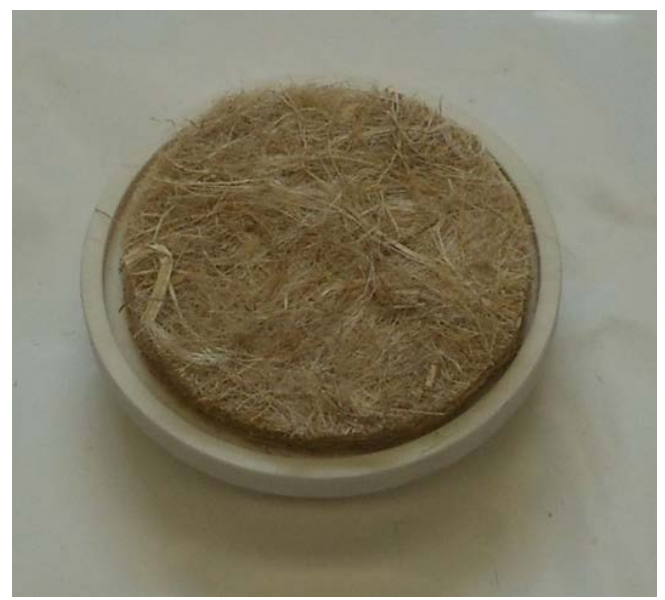

Figure 8. Test equipment with one of the samples.

\subsection{Fire reaction}


The fire reaction of hemp fibers was measured using calorimetric tests according to ISO 5660 method on a NOSELAB Cone calorimeter (Figure 9).

The cone calorimeter consists of a sample holder supported by a scale and an ignition system made with a conical radiant resistance and an electric ignitor. The test specimen, measuring $100 \mathrm{~mm} \times 100 \mathrm{~mm}$, is subjected to the action of the radiant cone which imposes on its surface a pre-established thermal power, up to $50 \mathrm{~kW} \cdot \mathrm{m}^{-2}$, representative of the thermal action produced in the initial phase of the fire. The electric ignitor acts above the surface of the specimen and ignites the distillation gases released during thermal exposure. The effluents of the fire are conveyed along an extraction duct that houses the probes for sampling the atmosphere samples and the measuring instruments.

The net heat of combustion of the products is proportional to the amount of oxygen required for combustion, therefore the Heat Release Rate (HRR) is determined through the measurement of oxygen consumption.

The peak value of the HRR curve (pHRR) determines the intensity of the developed fire.

The instrument also returns:

1) the Effective heat of combustion (EHC);

2) the Ignition time: time needed to have persistent flames to a given incident flow (fire propensity).

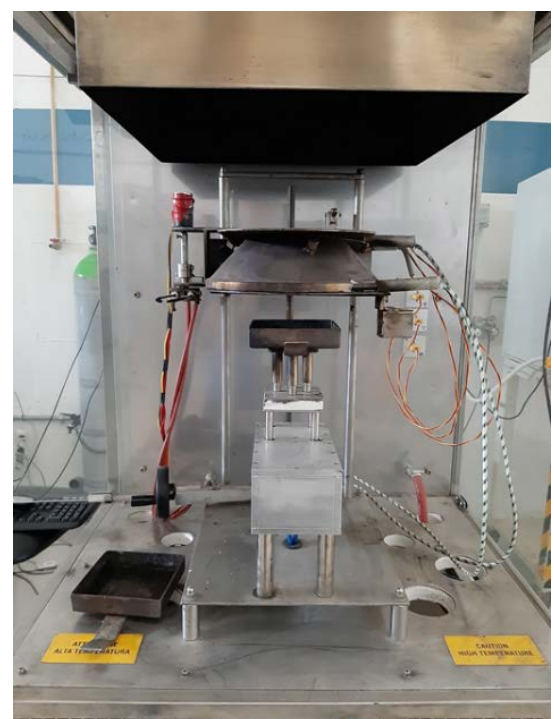

Figure 9. NOSELAB cone calorimeter.

\section{Results and discussion}

In accordance with the experimental method above explained, tests to determine the thermal conductivity of samples at $10^{\circ} \mathrm{C}$ - dry state - were carried out. Due to the intrinsic inhomogeneity of fibrous material such as hemp, the measures had a significant uncertainty. For this reason, the density values were reported to an equivalent cylinder with a size equal to the average one measured for the individual specimens.

The tests were repeated to verify the accuracy of experimental results. Also verification tests on reference calibration materials were realized to confirm what previously obtained.

The density and the thermal conductivity $\lambda_{10 \text {,dry }}$ results are reported in Table 1 .

Table 1. Thermal conductivity and density for hemp samples.

\begin{tabular}{cccccc}
\hline SAMPLE code & Carded & Pressed & $\begin{array}{c}\text { Density } \\
{\left[\mathrm{kg} \cdot \mathrm{m}^{-3}\right]}\end{array}$ & $\begin{array}{c}\text { Thickness } \\
{[\mathrm{mm}]}\end{array}$ & $\begin{array}{c}\text { Thermal conductivity } \\
{\left[\mathrm{W} \cdot \mathrm{m}^{-1} \cdot \mathrm{K}^{-1}\right]}\end{array}$ \\
\hline H & $\times$ & $\times$ & 147.0 & 5.6 & 0.050 \\
CH & $\checkmark$ & $\times$ & 226.3 & 3.0 & 0.042 \\
CPH & $\checkmark$ & $\checkmark$ & 132.6 & 3.5 & 0.040 \\
HSF & $\times$ & $\times$ & 59.8 & 4.8 & 0.047 \\
\hline
\end{tabular}

With regard to local hemp, the test results show that for all the samples, individually considered, to higher density values do not correspond higher conductivity values, as instead expected. Indeed, several studies assert a linear increase of thermal conductivity with density in the range investigated, because porosity decreases and an increasing transmission of heat in the solid phase by conduction takes place [23, 24]. It could be due to the presence of wood elements with macroscopic size in these materials. These elements, bigger than other fibers, pass through 
the sample along different directions and in a continuously way, facilitating the thermal flux passage. Due to this different composition, these samples cannot be considered to be equal to the other ones. Differences in thermal behavior of samples with and without wood elements with macroscopic size are also reported in Neuberger et al. [25] which states that if the heat flux is directed perpendicular to the direction of the stalks, the thermal conductivity is lower than that they obtained with heat flux in the direction along the stalks. And that the crushing of the stalk structure before the production of building materials of vegetable origin enables the subsequent production of panels with constant thermal insulation properties. In our work, the exfoliation of starting materials before the carding, to partially remove the wood fraction, contributed to the elimination of thermal bridges and, therefore, to the reduction of the thermal conductivity, decreasing from $0.05 \mathrm{~W} \cdot \mathrm{m}^{-1} \cdot \mathrm{K}^{-1}$ for $\mathrm{H}$ to $0.042 \mathrm{~W} \cdot \mathrm{m}^{-1} \cdot \mathrm{K}^{-1}$ and 0.040 $\mathrm{W} \cdot \mathrm{m}^{-1} \cdot \mathrm{K}^{-1}$ for $\mathrm{CH}$ and $\mathrm{CPH}$, respectively.

Moreover it is worth noticing that, despite the densities of $\mathrm{H}, \mathrm{CH}$ and $\mathrm{CPH}$ are from twice to almost four times that of HSF, the thermal conductivities are comparable. In principle, we can state that the elimination of the woody fraction from the local hemp allows reducing the thermal conductivity below the value of the commercial reference.

Table 2 highlights the results of thermal conductivity on empty and filled hollow bricks. Four measurements were performed for both the cases: as expected, the presence of hemp fibers allow a reduction of thermal conductivity of hollow bricks, from an average value of $0.20 \mathrm{~W} \cdot \mathrm{m}^{-1} \cdot \mathrm{K}^{-1}$ to $0.15 \mathrm{~W} \cdot \mathrm{m}^{-1} \cdot \mathrm{K}^{-1}$, confirming the effectiveness as insulation material oh hemp fibers.

Table 2. Measurement of thermal conductivity of hollow bricks.

\begin{tabular}{ccccc}
\hline Sample & $\begin{array}{c}\text { Average sample thickness } \\
{[\mathrm{mm}]}\end{array}$ & $\begin{array}{c}\text { Pressure } \\
{[\mathrm{MPa}]}\end{array}$ & $\begin{array}{c}\text { Density } \\
{\left[\mathrm{kg} \cdot \mathrm{m}^{-3}\right]}\end{array}$ & $\begin{array}{c}\text { Thermal conductivity } \\
{\left[\mathrm{W} \cdot \mathrm{m}^{-1} \cdot \mathrm{K}^{-1}\right]}\end{array}$ \\
\hline Empty brick & 78.8 & 500 & 641 & 0.198 \\
Empty brick & 78.8 & 500 & 653 & 0.211 \\
Empty brick & 77.9 & 500 & 649,2 & 0.197 \\
Empty brick & 79.6 & 500 & 615 & 0.205 \\
Filled brick & 79.3 & 500 & 684.2 & 0,148 \\
Filled brick & 79.5 & 500 & 700.2 & 0.143 \\
Filled brick & 79.4 & 500 & 690.6 & 0.152 \\
Filled brick & 78.7 & 500 & 704.8 & 0.153 \\
\hline
\end{tabular}

In addition, the standard deviation of results was very low in both the cases (Figure 10).

Thermal conductivity of bricks

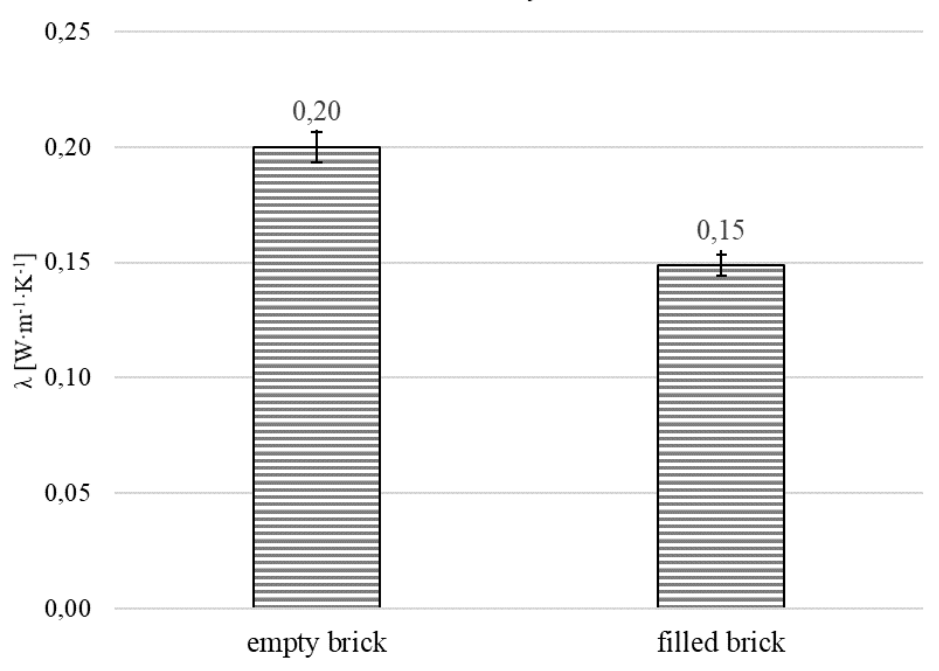

Figure 10. Thermal conductivity of empty and filled with hemp fibers bricks

With regard to vapor permeability, it has not been possible to obtain samples with uniform thickness, due to the composition of the material. Measurements performed on the five samples resulted in the thickness values reported in Table 3. 
Table 3. Measurement of the initial mass M0 of the system (g)

\begin{tabular}{ccc}
\hline Sample & $\mathrm{M}_{0}[\mathrm{~g}]$ & Average sample thickness [mm] \\
\hline $\mathrm{H}$ & 162.32 & 10.33 \\
$\mathrm{CH}$ & 160.79 & 14.28 \\
$\mathrm{CPH}$ & 161.61 & 22.91 \\
$\mathrm{HSF}$ & 156.51 & 20.65 \\
\hline
\end{tabular}

From these values, the water-vapor transmission rate $\mathrm{W}$ can be determined. From $\mathrm{W}$, the equivalent air layer thickness $\mathrm{s}_{\mathrm{d}}(\mathrm{m})$ and the water vapor resistance factor $\mu$ can be calculated, according to method described in the paragraph 2.4 .

Environmental average boundary conditions during the test in terms of temperature and relative humidity are the following:

1) Average temperature inside the sample: $23.8^{\circ} \mathrm{C}$;

2) Average external temperature: $20 \pm 2{ }^{\circ} \mathrm{C}$;

3) Internal relative humidity: $93.2 \%$, assumed to be equal to the nominal value guaranteed by the saturated KNO3 solution, since the space inside the cup is very small compared to the amount of solution, the foreseen humidity level can be maintained;

4) Relative humidity outside the sample: $32.9 \%$ (average value during the test).

Figure 11 highlights results obtained on the local hemp $(\mathrm{H}, \mathrm{CH}$ and $\mathrm{CPH})$. In particular, the obtained results show that during the initial transitory phase the mass variation is not linear and therefore it is excluded for the purposes of empiric determination of G. Test results underline high permeability values for all type of tested hemp, so that, after few days of evaluation, $\mathrm{KNO}_{3}$ solution was completely evaporated, as it is visible from the plateau of all the samples after the linear mass loss.

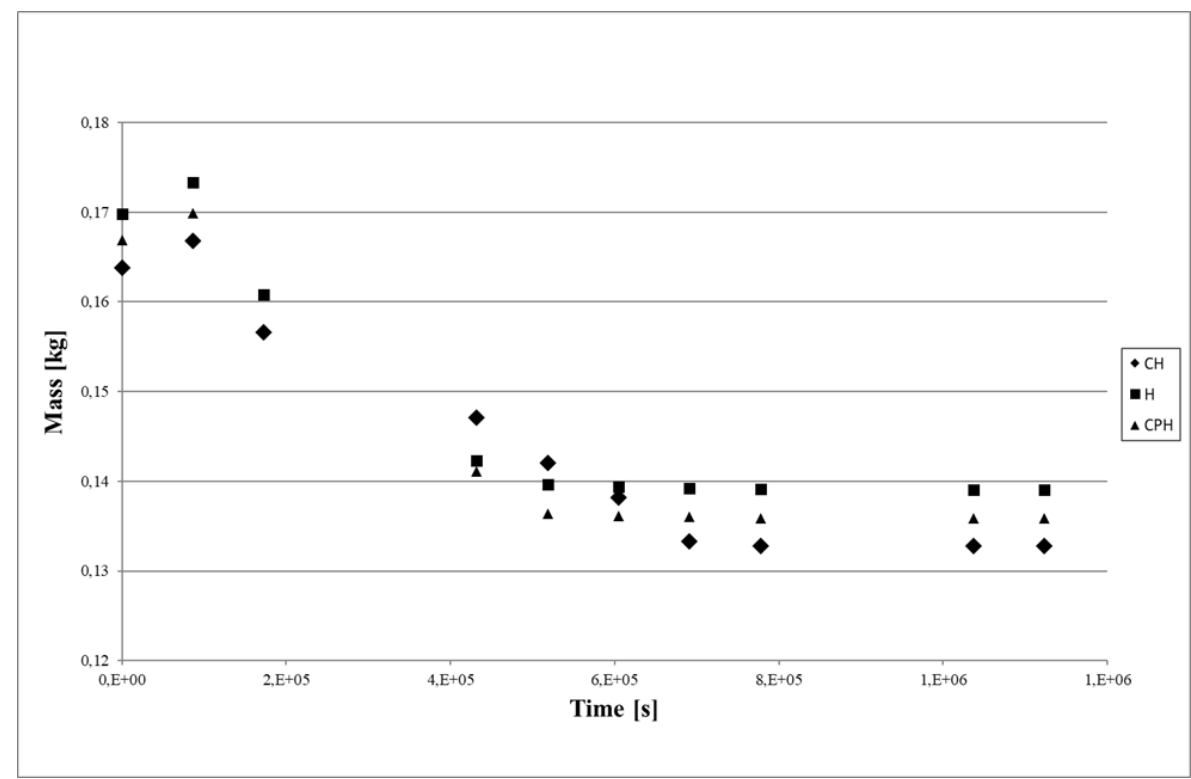

Figure 11. Water Vapor permeability determination: Mass vs Time correlation for samples investigated

Measured values obtained for both local hemps and the reference (HSF) allow to elaborate data according to equations (1) and (2) in order to determine the water-vapor resistance factor $\mu$ (Table 4).

Equivalent air layer thickness values for local hemps are between $0.036 \mathrm{~m}$ and $0.124 \mathrm{~m}$, while values for watervapor resistance factor are between 0.63 and 1.45. For the reference (HSF), 0.023 and 1.12 were the measured values of the equivalent air layer thickness and the water-vapor resistance factor, respectively.

Table 4. Water-vapor resistance factor and water-vapor diffusion-equivalent air layer thickness

\begin{tabular}{ccccc}
\hline Sample & $\mathrm{G}\left[\mathrm{kg} \cdot \mathrm{s}^{-1}\right]$ & $\mathrm{W}\left[\mathrm{kg} \cdot \mathrm{m}^{-2} \cdot \mathrm{Pa}^{-1} \cdot \mathrm{s}^{-1}\right]$ & $\mu$ & $\mathrm{S}_{\mathrm{d}}(\mathrm{m})$ \\
\hline $\mathrm{H}$ & $8.13 \mathrm{E}-08$ & $1.37 \mathrm{E}-08$ & 0.63 & 0.036 \\
$\mathrm{CH}$ & $5.74 \mathrm{E}-08$ & $9.44 \mathrm{E}-09$ & 1.45 & 0.124 \\
$\mathrm{CPH}$ & $6.07 \mathrm{E}-08$ & $1.01 \mathrm{E}-09$ & 1.26 & 0.115 \\
$\mathrm{HSF}$ & $5.34 \mathrm{E}-08$ & $8.50 \mathrm{E}-09$ & 1.12 & 0.023 \\
\hline
\end{tabular}


Experimental results underlines that the "as is it" hemp shows the lower value of water-vapor resistance factor, therefore it assures higher breathability when compared to carded and carded and pressed hemps, as well as with respect to HSF. Water-vapor resistance factors for $\mathrm{CH}$ and $\mathrm{CPH}$ are twice that of sample $\mathrm{H}$ : this can be explained with a greater compactness and a less porosity that the material takes when it is subjected to carding and pressing operations.

Cone calorimetric tests was performed according to ISO 5660 standard method at a heat flux of $50 \mathrm{~kW} \cdot \mathrm{m}^{-2}$, which is a normal irradiance level for the evaluation of fire behavior of materials, using a cone shaped heater. Exhaust flow rate was $24 \mathrm{l} \cdot \mathrm{s}^{-1}$ and the spark was continuous until the sample ignited.

Table 5 shows the results of the test carried out with the calorimetric cone. The samples consist only of local hemp show a value of pHRR less than $90 \mathrm{~kW} \cdot \mathrm{m}^{-2}$ as generally reported in the literature [26]. The results show a certain dispersion probably due to the intrinsic heterogeneity of the analyzed samples. Instead the samples prepared with the reference HSF showed a higher value of pHHR equal to $203 \mathrm{~kW} \cdot \mathrm{m}^{-2}$ certainly due to the presence of the thermoplastic fibers [27] which worsens the behavior in terms of fire reaction of insulation mat.

Table 5. Results of the Calorimetric test

\begin{tabular}{ccccc}
\hline Sample & $\begin{array}{c}\text { Time of ignition } \\
{[\mathrm{s}]}\end{array}$ & $\begin{array}{c}\text { Initial mass } \\
{[\mathrm{g}]}\end{array}$ & $\begin{array}{c}\text { Lost mass } \\
{[\mathrm{g}]}\end{array}$ & $\begin{array}{c}\mathrm{pHRR} \\
{\left[\mathrm{kW} \cdot \mathrm{m}^{-2}\right]}\end{array}$ \\
\hline $\mathrm{H}$ & 22 & 17 & 8 & 89 \\
$\mathrm{CH}$ & 22 & 22 & 11 & 78 \\
$\mathrm{CPH}$ & 24 & 20 & 10 & 84 \\
$\mathrm{HSF}$ & 22 & 51 & 38 & 203 \\
\hline
\end{tabular}

\section{Conclusions}

An experimental study was undertaken to understand the influence of some mechanical operations (carding and pressing) on hygrothermal properties of hemp fibers, in particular on thermal conductivity, vapor permeability and fire reaction. Hemp fibers (Cannabis sativa) were taken from local crops in Apulia (Italy) in the form of bulk material that we called "as it is" hemp fibers. On the other hand, some hemp fibers were carded and pressed. This kind of mechanical operations makes the hemp samples more workable and quite self-consistent even without the presence of binders.

Then, samples of nonwoven mats of hemp fibers were realized, in accordance with the standards for measurement of thermal conductivity, vapor permeability and fire reaction. Measurements performed on them, and compared with those performed on a commercial product made with $90 \%$ of hemp and $10 \%$ of synthetic fibers, allowed to detect the following findings:

1) Hemp fibers in the form of bulk materials and not submitted to pressing or carding, show higher thermal conductivity value with respect to carded and pressed hemp fibers. In this case, this phenomenon is explained with the presence of wood elements with macroscopic size in the "as it is" hemp, which enhance the thermal flux along different directions, reducing the thermal resistance;

2) The thermal conductivity of not carded and not pressed hemp fibers is a little higher than that of the commercial product. Nevertheless, the elimination of the woody fraction from the local hemp fibers allows reducing the thermal conductivity below the value of the reference;

3) Filling the holes of hollow bricks with hemp fibers allows a reduction of the thermal conductivity, that decreases from $0.20 \mathrm{~W} \cdot \mathrm{m}^{-1} \cdot \mathrm{K}^{-1}$ to $0.15 \mathrm{~W} \cdot \mathrm{m}^{-1} \cdot \mathrm{K}^{-1}$;

4) The water-vapor resistance factors for carded and pressed hemp fibers are twice that of "as it is" samples, and comparable with that of the commercial product. We can state that hemp fibers in the form of bulk materials assure higher breathability when compared to carded and carded and pressed hemps, as well as to the commercial product used as reference;

5) The value of the pHHR of all the local hemp fibers samples investigated ( $\mathrm{H}, \mathrm{CH}$ and $\mathrm{CPH})$ is influenced by the manufacturing process but remains under the value of $90 \mathrm{~kW} \cdot \mathrm{m}^{-2}$. Conversely, the presence of synthetic commingled fibers in the commercial product causes an increase in the pHHR up to $200 \mathrm{~kW} \cdot \mathrm{m}^{-2}$.

\section{Acknowledgment}

This work was supported by EFFEDIL Project (EFFicient Energy builDing Innovative soLutions Grant no: PON02_00323_2938699) funded by Italian Ministry of Education and Research and by SOS Project (Advanced and eco-sustainable materials for applications in Smart Operating Shelter multifunctional, intelligent, reconfigurable Grant no: 9751YR7) funded by POR Puglia FESR-FSE 2014.

The authors of the present work thank Mr. Gianpaolo Casciaro for the cooperation in this project. 


\section{References}

[1] Mardiana A, Riffat SB. Building energy consumption and carbon dioxide emission: Threat to climate change. J Earth Sci Climate Change. 2005; S3.

[2] Yau YH, Hasbi S. A review of climate change impacts on commercial buildings and their technical services in the tropics. Renewable and Sustainable Energy Reviews. 2013; 18: 430-441.

[3] Directive 2010/31/EU of the European Parliament and of the Council of 19 May 2010 on the energy performance of buildings. https://eur-lex.europa.eu/legal-content/EN/ALL/?uri=celex\%3A32010L0031.

[4] Papadopoulos AM. State of the art in the thermal insulation materials and aims for future developments. Energy and Buildings. 2005;37:77-86.

[5] Jelle BP. Traditional, state-of-the-art and future thermal building insulation materials and solutions properties, requirements and possibilities. Energy and Buildings. 2011;43:2549-2563.

[6] Sassoni E, Manzi S, Motori A, Montecchi M, Canti M. Novel sustainable hemp-based composites for application in the building industry: Physical, thermal and mechanical characterization. Energy and Buildings. 2014;77:219-226.

[7] Costantine G, Maalouf C, Moussa T, Polidori G. Experimental and numerical investigations of thermal performance of a Hemp Lime external building insulation. Building and Environment. 2018;131:140-153.

[8] Amziane S, Arnaud L. Bio-aggregate-based building materials: applications to hemp concrete; ISTE Ltd.: London, UK; John Wiley \& Sons, Inc.: Hoboken, NY, USA; 2013.

[9] Stevulova N, Čigášová J, Schwarzova I, Sicakova A, Jozef J. Sustainable bio-aggregate-based composites containing hemp hurds and alternative binder. Buildings. 2018;8.. doi 10.3390/buildings8020025.

[10] Aversa P, Palumbo D, Donatelli A, Tamborrino R, Ancona F, Galietti U, Luprano VAM. Infrared thermography for the investigation of dynamic thermal behaviour of opaque building elements: Comparison between empty and filled with hemp fibers prototype walls. Energy and Buildings. 2017;152:264-272.

[11] Delannoy G, Marceau S, Glé P, Gourlay E, Guéguen-Minerbe M, Diafi D, Nour I, Amziane S, Farcas F. Aging of hemp shiv used for concrete. Materials and Design. 2018;160:752-762.

[12] Donatelli A, Cuna D, Tagliente MA, Protopapa ML, Mevoli A, Aversa P, Blasi C, Capodieci L, Luprano VAM. Effect of treatments on the aging behaviour of hemp fibers for building construction in the Mediterranean Area. Journal of Building Engineering. 2017;11:37-47.

[13] Mustata A, Mustata FSC. Moisture absorption and desorption in flax and hemp fibers and yarn. Fibers \& Textiles in Eastern Europe. 2013;21, 3(99):26-30.

[14] Mâlcomete O. et. al. Cap. 1.2. Proprietatile generale ale fiberlor textile, din Manualul inginerului textilist, Vol. 1, The Book of the Textile Engineer, AGIR Ed, Bucharest; 2003. p.54-55.

[15] Panthapulakkal S, Sain M. Studies on the water absorption properties of short hemp-glass fiber hybrid polypropylene composites. Journal of Composite Materials. 2007;41(15):1881-1883.

[16] Dhakal HN, Zhang ZY, Richardson MOW. Effect of water absorption on the mechanical properties of hemp fiber reinforced unsaturated polyester composites. Composites Science and Technology. 2007;67 (7-8):16741683.

[17] Latif E, Ciupala MA, Tucker S, Wijeyesekera DC, Newport DJ. Hygrothermal performance of wood-hemp insulation in timber frame wall panels with and without a vapor barrier. Building and Environment. 2015;92:122-134.

[18] Kozłowski R, Mieleniak B, Muzyczek M, Mańkowski J. Development of insulation composite based on FR bast fibers and wool. In: International Conference on Flax and Other Bast Plants, Poznań, Poland, 2008.

[19] DTC-300 heat flow meter software \& operation manual.

[20] ASTM E1530-2011. Standard test method for evaluating the resistance to thermal transmission of materials by the guarded heat flow meter technique.

[21] EN 12667:2001. Thermal performance of building materials and products - determination of thermal resistance by means of guarded hot plate and heat flow meter methods - products of high and medium thermal resistance.

[22] EN 12664:2002. Thermal performance of building materials and products. Determination of thermal resistance by means of guarded hot plate and heat flow meter methods. Dry and moist products of medium and low thermal resistance.

[23] Lekavicius V, Shipkovs P, Ivanovs S, Rucins A. Thermo-insulation properties of hemp-based products. Latvian Journal of Physics and Technical Sciences. 2015;52(1):38-51.

[24] Sekino N. Density dependence in the thermal conductivity of cellulose fiber mats and wood shavings mats: investigation of the apparent thermal conductivity of coarse pores. Journal of Wood Science. 2015;62:15231526. 
[25] Neuberger P, Kic P. “Thermal conductivity of natural materials used for thermal insulation” Engineering for rural development, 420-424 Jelgava: Latvia University of Life Sciences and Technologies. doi:10.22616/ERDev2017.16.N082.

[26] Advanced high strength natural fiber composites in construction, Book 2017 Edited by Mizi Fan and Feng Fu. P. 479-508.

[27] Zhao HB, Wang YZ. Design and synthesis of PET-Based copolyesters with flame-retardant and antidripping performance. Macromolecular Rapid Communications. 2017;38(23):1700451. 